\title{
ESTUDO DE CASO SOBRE A ABORDAGEM DO COMPONENTE CURRICULAR DE HISTÓRIA: UMA VISÃO INTERDISCIPLINAR
}

\section{REVISÃO INTEGRATIVA}

VIANA, Maria Betânia Rossi ${ }^{1}$

VIANA, Maria Betânia Rossi. Estudo de caso sobre a abordagem do componente curricular de História: Uma visão interdisciplinar. Revista Científica Multidisciplinar Núcleo do Conhecimento. Ano 05, Ed. 10, Vol. 04, pp. 98-108. Outubro de 2020. ISSN: 2448-0959, Link de

acesso: https://www.nucleodoconhecimento.com.br/educacao/uma-visaointerdisciplinar

\section{RESUMO}

Este artigo nasceu da inquietação em relação a fragmentação da História ensinada na Escola Estadual Professora Maria Curtareli Lira, no Ensino Médio, o qual descreve o árduo caminho percorrido pelo componente curricular de História, desde a colonização do Brasil até os dias atuais e como a interdisciplinaridade é importante, sendo pouca abordada ou simplesmente inexistente nas aulas do componente curricular de história. Cujo objetivos descrever um breve histórico do componente curricular de história, conceituar a interdisciplinaridade bem como especificar como ela está inserida no panorama educacional brasileiro. A metodologia empregada foi um levantamento bibliográfico dos autores pertinentes a temática, concluindo com os embates sobre a interdisciplinaridade e a forma integradora que é retratada na Base Nacional Comum curricular.

Palavras-chave: História, interdisciplinaridade, Base Nacional Comum Curricular.

\footnotetext{
${ }^{1}$ Mestra em Ciências da Educação.
} 


\section{INTRODUÇÃO}

Este artigo científico discorre sobre um tema muito debatido, a interdisciplinaridade, a qual iniciou-se nas universidades, posterior a Segunda Guerra Mundial, com o surgimento de uma realidade que traz em seu calabouço mudanças drásticas, provocadas pela bomba atômica e todas as atrocidades vivenciada nos campos de concentração.

Ambas as situações são resultantes do uso distorcido das Ciências Moderna, trazendo à tona a necessidade de se reconstruir a forma em que a sociedade utiliza toda esta nova tecnologia, o comprometimento com as consequências que o uso indevido delas traz para a humanidade.

Com os vários questionamentos, observou-se que os saberes científicos, na qualidade de produtor de conhecimentos não suportariam continuarem sendo abordados isoladamente, trouxe à baila a necessidade de ruptura com a organização fragmentada dos saberes escolares.

Apesar de todos os estudos e debates sobre esta nova visão, é ainda pouco aplicado no cotidiano escolar, quando se deseja ensinar e ao mesmo tempo aprender de forma integra e não esfaceladas em áreas de conhecimento. Está revisão bibliográfica está voltado para a interdisciplinaridade aplicada no componente curricular de história.

A abordagem do tema que deu origem a este trabalho foi a História num foco Interdisciplinar, na Escola Estadual Professora Maria Curtarelli Lira, na qual atendese alunos do $6^{\circ}$ ano ao $9^{\circ}$ ano do Ensino Fundamental e $1^{\circ}$ ano ao $3^{\circ}$ ano do Ensino Médio, nos períodos matutino, vespertino e noturno. Está localizada no município de Apuí, ao Sul do Estado do Amazonas, no meio da floresta Amazônica.

A clientela atendida, foge ao padrão da população amazonense tradicional, pois na sua maioria é formada por imigrantes de várias regiões do país, onde prevalece os imigrantes sulista, que vieram para região amazônica em busca de melhores condições de vida. 
A cultura típica predominante é o churrasco, o chimarrão, festas Juninas e o Rodeio. Grande parte do alunado atendido pela instituição mora na zona urbana e trinta por cento mora na zona Rural, sendo assim, dependendo de transporte escolar para chegar à escola.

A comunidade em que ela está inserida é bem participativa, colabora sempre que possível com a instituição escolar no desenvolvimento dos projetos educacionais, nos cuidados com a infraestrutura da escola e no desenvolvimento de palestras e orientações aos alunos.

Ao se observar o trabalho desenvolvido pelos docentes, na rotina diária da Instituição educacional, detectou que componentes curriculares eram abordados de uma maneira totalmente fragmentada, sem um elo entre si, permanecendo os assuntos soltos e sem sentido.

A partir desta inquietação buscamos mais informações teóricas sobre interdisciplinaridade e a viabilização na aplicação dela quando se deseja alcançar o sucesso no ensino-aprendizagem, já que ela faz parte das normativas educacionais.

Discorre-se sobre o caminho percorrido pelo Componente Curricular de História desde o início do ensino aprendizado no Brasil através dos Jesuítas até sua atual configuração na BNCC, buscando embasamento em teóricos de como trabalhá-la interdisciplinarmente com as demais ciências, bem como o palco onde surgiu está visão e as suas contribuições para um aprendizado eficaz dos discentes.

\section{A INTERDISCIPLINARIDADE E O COMPONENTE CURRICULAR DE HISTÓRIA NA EDUCAÇÃO BRASILEIRA}

A história no Brasil, retrata a utilização do Componente Curricular de História, como fonte de leitura pelos jesuítas para ensinar a ler e escrever no ensino elementar. Usouse a constituição do Império e a História do Brasil como material para este ensino aprendizado. 
As propostas em vigência na educação formal, na época, não diferenciavam as ideias morais, das histórias políticas estaduais nem das culturas populares.

Os professores das escolas elementares deveriam, segundo os planos de estudos propostos em 1827, utilizar para o ensino da leitura, entre outros textos, "a Constituição do Império e História do Brasil". O ensino de História associava-se a lições de leitura, para que se aprendesse a ler utilizando temas que incitassem a imaginação dos meninos e fortificassem o senso moral por meio de deveres para com Pátria e seus governantes (BITTENCOURT, 2018, p. 48).

No período Imperial, para legitimar a aliança entre a Igreja e o Estado, prevaleceu o ensino religioso nos currículos das Escolas de Primeiras Letras, também no Nível Secundário. Apesar de todo o contexto e intenções legislativas, o Componente Curricular de História era uma disciplina não obrigatória nos currículos das Escolas Elementares da época, foi inserido no Ensino Secundário após o ano de 1885. Posteriormente, criou-se programas de História para as Escolas Elementares.

O vínculo religioso que o país vivenciou na educação brasileira durante os primeiros séculos, foi difícil de ser rompido, apesar da inserção da História Nacional como matéria constitutiva do currículo das Escolas Elementares, a seu lado via também a História Sagrada como conteúdo de Educação Moral e Religiosa.

Os conteúdos, por sua vez, não foram definidos claramente, embora houvesse propostas para o ensino da História geral profana, da História sagrada e da História do Império do Brasil. A consolidação de planos de estudos só ocorreu a partir do momento em que o Colégio Pedro II, criado em 1837, instituiu seus programas curriculares, introduzindo, a partir de 1838, o ensino de História ao longo de suas oito séries. (FONSECA, 2006, p. 43)

No ano de 1870, ocorre a transformação dos programas curriculares das Escolas Elementares que sofrem influências das percepções cientificistas que travaram confrontos com os setores conservadores que consequentemente estavam vinculados a uma Educação moralizante coordenada pela Igreja Católica.

Os programas curriculares das escolas elementares foram ampliados e matérias escolares inovadoras na época foram a ele incorporado como: as matérias escolares 
de ciências físicas, de História Natural. Tendo nela incluso tópicos sobre História do Brasil, História Regional História e Geografia Universal. Tendo em vista que o referido Componente Curricular percorreu um longo cominho até se tornar disciplina de área específica de acordo com os PCNs:

No decorrer dos anos 70 as lutas dos profissionais desde a sala de aula até a universidade, ganharam expressão com o crescimento das associações de historiadores [...] e seu engajamento na batalha pela volta de história e geografia aos currículos escolares e extinção dos cursos de Licenciatura em Estudos Sociais (PCNs, 1991, p.27).

Os pensadores brasileiros cada vez mais indignados com a posição que a História ocupava no currículo escolar, buscavam incessantemente uma renovação dela e o início desta mudança foi garantida, de acordo com Penteado:

Segundo a lei e o parecer 853/71, "Estudos Sociais é uma área de estudo que tem por objetivo a integração espaço-temporal do educando, servindo-se para tanto dos conhecimentos e conceitos da História e Geografia e das outras ciências humanas - Antropologia, Sociologia, Política, Economia - como instrumento necessários para a compreensão da História e para o ajustamento ao meio social a que pretende o educador (PENTEADO, 2005, p.20).

Novas reorganizações foram pensadas e colocadas em prática, no currículo das Escolas Primárias o objetivando conceber uma proposta de História Profana com maior abrangência e eliminar a História Sagrada.

Pois, no período Imperial o programa curricular já propunha esta separação, mas na prática, no momento do ensino aprendizagem, não podia se afirmar sobre a História que era ensinada.

Apesar da reformulação, vivenciou-se nos programas de História do Brasil o mesmo modelo adotado pela História Sagrada, no qual, apenas substituíam as narrativas morais que descreviam a vida dos santos e ações heroicas de determinados personagens daquele período, que acreditavam serem construtores da nação, como as autoridades do governo e os clérigos. 
A disposição dos episódios era organizada de acordo com a sucessão de reis, batalhas contra povos estrangeiros que tentavam invadir os territórios, todos os acontecimentos que estavam de certa forma ligados a independência, também a formação do Estado Nacional , todos os fatos que levariam o País a se tornar uma grande nação.

A metodologia utilizada na época, em sala de aula, no momento do desenvolvimento dos conhecimentos a serem adquiridos com Componente Curricular de História era a tradicional, baseada totalmente na memorização dos acontecimentos históricos da forma que eles eram apresentados e na repetição de textos.

Novos desafios políticos e educacionais são vivenciados pelo Brasil no final do século XIX, os mais relevantes a serem citados são: libertação dos Escravos através da Lei Aurea Assinada pela Princesa Isabel; Proclamação da República; as mudanças no campo trabalhista e a migração; dentre outros fatores.

A História incorpora-se de conteúdos humanísticos e pacifistas, voltados as análises dos processos de desenvolvimento econômico das sociedades do período, os avanços das tecnologias, das ciências e da cultura.

A partir de 1930, começam a despontar propostas de substituição dos componentes curriculares de História e Geografia pelo componente curricular de Estudos Sociais, inspirados nas escolas norte Americana. Se aperfeiçoando apenas em 1950, através de estudos pedagógicos.

No período militar, o intuito era que a história transcorresse somente o que era de interesse dos militares, permanecendo por muito tempo uma maneira de ensinar civilidade e obediência aos mesmos. Jamais transgredindo a normas e sofrendo coerções de diversas formas, sendo por um período até certo ponto sem muito valor no currículo escolar. Neste período do contexto educacional brasileiro, o componente Curricular de História não era visto como uma disciplina.

Durante a maior parte do período da ditadura militar (1964-1985), as disciplinas de História e Geografia foram eliminadas do Ensino 
Fundamental e substituídas pelos conteúdos de Educação Moral e Cívica e de Organização Social e Política do Brasil (OSPB) (ZUCCHI, 2012, p. 20).

Contudo, via-se o aumento e ampliação das oportunidades de acesso as Instituições educacionais da época, para a maioria da população que até aquele momento estavam a margem do ensino. Por outro lado, havia uma degradação da qualidade da Educação Pública, devido a diversos fatores políticos, educacionais e econômicos.

No ano de 1980, tem-se a democratização dos conhecimentos educacionais os quais, passaram a ser examinados e reorganizados através de reformas curriculares. Houve uma drástica mudança da clientela escolar, a qual era formada por diversos grupos sociais, os quais vivenciavam um intenso processo de êxodo rural. Com essa acentuada diferença de classe social forçaram uma mudança no contexto educacional.

Com o fim do regime militar, em meados da década de 1980, entidades formadas por professores, pesquisadores e outros profissionais ligados às áreas de História e Geografia [...]deram início a um processo de debate, com o intuito de tornar novamente essas disciplina presentes e independentes nos currículos da escolas brasileira (ZUCCHI, 2012, p. 21).

Mas, a história dos dias atuais nas séries/anos iniciais do Ensino Fundamental, ainda é repassada para os discentes de uma forma um tanto romantizada e fora da contextualização do cotidiano vivenciado por ele, contudo que os docentes têm sua formação em pedagogia, e precisam ensinar todos os componentes curriculares que a grade exige.

É muito difícil abandonar a educação tradicional na qual a maioria formou-se. Nesse contexto de ensino a História não traz significância, os discentes não sentem vontade em aprendê-la, a vendo como uma simples matéria decorativa que se torna irrelevante para a seu cotidiano e sua vida ocupacional.

Acredito que a História, em todas as suas dimensões, é essencialmente formativa. Assim, seu ensino, os sujeitos, as aprendizagens, os saberes, as práticas, as experiências didáticas têm uma enorme importância para 
a vida social, para a construção da democracia e da cidadania (GUIMARÃES, 2013, p. 21).

A Interdisciplinaridade começou a ser abordada no Brasil a partir da Lei № 5.692/71. A partir deste momento, a sua presença no campo da educação brasileira tem feito presença marcante, principalmente, com a nova Lei de Diretrizes e Bases № 9.394/96, com os Parâmetros Curriculares nacionais e atualmente também, é componente integrante da Base Nacional Comum Curricular, que foi homologada em 20 de dezembro de 2017[2].

Mais ou menos a partir de 1994, antes mesmo do aparecimento dos Parâmetros Curriculares Nacionais para o ensino fundamental, já surgiam propostas de ensino de História que procuravam incorporar aquelas tendências, independentemente de sua existência nos programas curriculares oficiais (FONSECA, 2006, p. 62)

A Interdisciplinaridade, influenciou fortemente a legislação educacional e as propostas curriculares, tornando-se peça primordial, presente na alocução e no trabalho educacional dos docentes, que buscam ensinar os componentes curriculares de forma integra e não divididas em temas.

O emprego da interdisciplinaridade como metodologia de ensino para o andamento da integração dos objetos de conhecimento de um componente curricular com outros componentes curriculares. Proposta inserida na Base Nacional Comum Curricular que contribui para uma maior abrangência do ensino-aprendizado do alunado. Através da análise de estudos, pode-se observar, que a interdisciplinaridade ainda é desconhecida em sua totalidade, como também a sua importância e viabilidade na formação acadêmica de nossos discentes.

No Brasil, conceituamos Interdisciplinaridade por uma nova atitude diante da questão do conhecimento, da abertura à compreensão de aspectos ocultos do ato de aprender e dos aparentemente expressos, colocando-os em questão (FAZENDA, 2011, p. 21).

Existe a possiblidades de interação entre os Componentes Curriculares distintos, pode-se ponderar esta interação como uma forma de complementação ou suplementação, a qual conduz a perspectiva de uma elaboração de um conhecimento 
crítico-reflexivo, o qual deve ser prestigiado paulatinamente no ensino-aprendizado em classe.

A formação na educação pela e para a Interdisciplinaridade se impõe e precisa ser concebida sob bases específicas, apoiadas por trabalhos desenvolvidos na área, referendados em diferentes ciências que pretendem contribuir desde as finalidades particulares da formação profissional até a atuação do professor (FAZENDA, 2011, p. 23).

Surgindo nesta perspectiva, uma maneira de superar o esfacelamento entre os Componentes Curriculares. Possibilitando assim uma conversação entre estes, relacionando-os entre si para uma maior compreensão da realidade em que se está inserido. A interdisciplinaridade procura correlacionar os Componentes Curriculares quando confronta os temas dos assuntos em estudo.

A interdisciplinaridade necessita de ações disciplinares que comungam de interesses em comum. Mas somente será eficaz se as metas educacionais traçadas forem atingidas. Se estas metas forem estabelecidas com antecedência e que todos os profissionais da instituição educacional as compartilhem e colaborem no alcance delas.

A interdisciplinaridade oferece uma nova postura diante do conhecimento, uma mudança de atitude em busca do contexto do conhecimento, em busca do ser como pessoa integral. A interdisciplinaridade visa garantir a construção de um conhecimento globalizante, rompendo com os limites das disciplinas. O objetivo da construção de uma didática e de uma pesquisa interdisciplinares é a explicitação do contorno ambíguo dos movimentos e das ações pedagógicas - apenas o exercício da ambiguidade poderá sugerir a multiface do movimento e, por conseguinte, do fenômeno pesquisado (FAZENDA, 2011, p. 27).

O uso da interdisciplinaridade, deve ser empregada na docência, estimulando no docente um comportamento inovador, transcende o que está retratado na Base Nacional Comum Curricular, porquanto se torna uma necessidade de que ele tome uma postura intrínseca, utilizando metodologias e didáticas apropriada para esta perspectiva. 
Portanto, por meio de uma instrução interdisciplinar, com posicionamento focado no aspecto histórico-crítico, no qual os docentes proporcionarão aos seus discentes um aprendizado eficiente para a vida de cada um, em sua complexidade, de modo que o mundo atual não quer fragmentações exige-se o todo, algo completo.

A História é uma disciplina escolar que tem (ou deveria ter) profunda relação com a própria prática sociopolítica e cultural, mas que muitas vezes se torna um conhecimento esotérico e enigmático para os alunos, fenômenos este que acreditamos estar de alguma forma relacionado com a ação dos professores (MONTEIRO, 2010, p. 27).

No componente curricular de história a interdisciplinaridade está enraizada no desenrolar do seu ensino-aprendizado, pois todos os componentes curriculares têm sua ligação com ela. Podemos elencar várias metodologias e disciplinas afins, desde uma simples fotografia, uma carta, um relato de tudo, podemos abordar de forma interdisciplinar.

Tendo em vista, que tanto os objetos, os componentes curriculares, como as pessoas, trazem em seu arcabouço uma história. Nas quais fazem parte da história e são produtores de suas próprias histórias.

\section{CONCLUSÃO}

Nota-se, no campo de pesquisa, os estudos historiográficos e na interdisciplinaridade em discussão no Brasil, um amplo avanço desde seu surgimento, focando não somente na teorização.

A busca efetiva de possibilidades no campo de pesquisa. No momento do ensino aprendizado em sala de aula, nota-se a necessidade de se ter uma integração eficaz entre os diferentes níveis de aprendizagem dos Componentes Curriculares.

Nos grupos de historiadores que pesquisaram a temática, tem aqueles que defendem a teoria da filosofia do sujeito, na qual o sujeito e o objeto tornam-se autônomos. Em compensação há uma perspectiva histórica, na qual o sujeito e o objeto são indissociáveis, levando - se em conta seus contextos históricos - sociais. 
A Legislação Educacional Brasileira, traz em seu calabouço uma necessidade de adequação da educação brasileira em todas as suas esferas e níveis de integração das diversas vertentes, construída pelos saberes científicos de cada área do conhecimento.

As Universidades formam o Professor na parte Teórica, mas somente no exercício da profissão, na prática diária e na experiência do cotidiano escolar o professor adquire experiência, também aprende e reaprende com seus discentes. Ninguém nasce professor, mas torna-se professor. Assim, a formação profissional dele é marcada pelo desenvolvimento social e histórico no recinto escolar com seus discentes.

Nota-se na Base Nacional Comum Curricular uma preocupação mais profunda do que outros documentos educacionais com a interdisciplinaridade e a contextualização. Cabe a cada docente se preparar, organizar suas aulas e desenvolver projetos, visando, transpor essa fragmentação que tem entre os componentes curriculares nas escolas brasileira.

Sendo de suma importância, destacar, que no trabalho interdisciplinar não pretende à aniquilação dos componentes curriculares, almeja o oposto, pois ele estima a existência da disciplinarização.

A interdisciplinaridade que este artigo retrata, os componentes curriculares não têm suas especificidades desvinculadas e nem a importância. Mas, uma ligação entre si, onde todos os componentes curriculares se interligam, criando vínculos, onde os discentes irão aprender os conteúdos de uma forma integrada e não esfacelada.

A constantes mudanças vivenciada pelas instituições educacionais e os palcos de constantes debates sinalizam para um repensar da História de uma forma geral, pois não existem verdades absolutas. O processo de construção deve ser sempre questionado, para que estejamos sempre em reconstrução e reestruturação.

Principalmente, no campo educacional, em busca de uma aprendizagem de excelência, na qual possamos ter sempre uma linha de vínculo do Componente Curricular de História com os demais componentes curriculares. 


\section{REFERÊNCIAS}

ASSOCIAÇÃO BRASLIEIRA DE NORMAS TECNICAS. 6023: Informação e Técnicas, Rio de Janeiro, 2002.

BITTENCOURT, C. M. F. Ensino de História: Fundamentos e Métodos. 5. ed. São Paulo: Cortez, 2018.

BORGES, V. P. O que é História. Tatuapé, SP: Brasiliense, 2017.

BRANCO, E. P. et al. A implantação da base nacional comum curricular no contexto ds politicas neoliberais. Curitiba: Appris, 2018.

BRASIL, B. N. C. C. Educação é a Base. Brasilia, MEC/CONSED/UNDIME, 2017. Disponivel em: <http:// basenacionalcomum.mec.gov.br/imagens_publicacao.pdf>. Acesso em: 21 Abril 2019.

BRODBECK, M. D. S. L. Vivenciando a História - Metodologia de Ensino da História. Curitiba: Base Editorial, 2012.

FAZENDA, I. C. A. Integração e Interdisciplinaridade no Ensino Brasileiro: Efetividade ou ideologia. 6. ed. São Paulo: Loyola, 2011.

FONSECA, T. N. D. L. E. História \& Ensino de História. São Paulo: Autentica, 2006.

GUIMARÃES, S. Didática e Pratica de Ensino de História. 13. ed. Campinas: PAPIRUS, 2013.

. Interdisciplinaridade: História,Teoria e Pesquisa. 14. ed. São Paulo: Papirus, 2007.

. Ministério da Educação e Cultura. LDB- Lei no939/96, de 20 de dezembro de 1996. Estabelece diretirzes e bases da Educação Nacional Brasilia:MEC, 1996. 
MONTEIRO, A. M. Professores de Historia: Entre Saberes e Práticas. 2. ed. Rio de Janeiro: Mauad X, 2010.

PACHECO, R. A. Ensino de História e Patrimonio Cultura: Um Percurso Docente. Jundaí, SP: Paco, 2017.

PENTEADO, H. D. Metodologia do Ensino de História e Geografia. São Paulo: cortez, 2005.

Secretaria de Educação Fundamental. Parametros Curriculare Nacionais: História/Geografia, Brasília: MEC/SEF, 1998.

ZUCCHI, B. B. O Ensino de História nos Anos Iniciais do Ensino Fundamental: teoria, conceitos e uso de fontes. São Paulo: SM Ltda, 2012.

\section{APÊNDICE - REFERÊNCIA DE NOTA DE RODAPÉ}

2. Tomando como referência a data 20 de dezembro de 2017 , dia em que a BNCC do Ensino Fundamental foi homologada pelo Ministério da Educação, a BNCC deveria ser implementada a partir de dezembro de 2019. Levando em consideração, que o ano letivo se inicia em fevereiro, no mais tardar no início do ano letivo de 2020.

Enviado: Fevereiro, 2020.

Aprovado: Outubro, 2020. 